\title{
Factor structure of the CES-D in an impoverished African American sample
}

\author{
Mitchell Porter (iD) 1,*, Youn-Jeng Choi (iD) 2 , Sara Tomek (iD ${ }^{3}$
}

${ }^{1}$ Gardner-Webb University, 110 South Main Street, PO Box 7304, Boiling Springs, NC 28017

${ }^{2}$ The University of Alabama, Carmichael Hall, Box 870231, Tuscaloosa, AL 35487

${ }^{3}$ Baylor University, One Bear Place \#97301, Waco, TX 76798

\section{ARTICLE HISTORY}

Received: 17 April 2019

Revised: 24 July 2019

Accepted: 13 November 2019

\section{KEYWORDS}

Factor analysis, CES-D,

African American, Impoverished

\begin{abstract}
The Center of Epidemiological Studies Depression scale (CES-D) has been used for decades to identify symptomatology of depression in individuals. Overtime, the factor structure of the scale has been both confirmed and challenged when applied to different population samples. The present study explores the factor structure in population sample consisting of impoverished African American parents $(N=1,020)$, and the data were collected from the Mobile Youth Study (MYS). Two-, four-, and higher-order models were used to identify the best fitting model. The results indicate that the most parsimonious model is a two-factor structure.
\end{abstract}

\section{INTRODUCTION}

The factor structure of the Center for Epidemiological Studies Depression Scale (CES-D) has been challenged through the decades. While Radloff (1977) originally proposed a four-factor structure, other studies have proposed that a two- or three-factor structure may be sufficient (Miller, Markides, \& Black, 1997; Manson, Ackerson, Dick, Baron, \& Fleming, 1990). In fact, it has even been proposed that one factor solutions may be more desirable for interpretation than multiple factor solutions (Turvey, 1999), and even as many as five-factors has been proposed (Stroup-Benham, Lawrence, \& Trevifio, 1992). The purpose of this paper is to investigate the factor structure and find the most parsimonious model of the CES-D within a specific population sample: impoverished African American parents of at-risk behavior students.

There are a number of rating scales designed to measure depression. Some are meant to be completed by researcher, e.g. the Hamilton Depression Scale (Hamilton, 1960) and the Montgomery-Åsberg Depression Rating Scale (Montgomery \& Asberg, 1979), while others are designed to be completed by the patients themselves such as the Beck Depression Inventory (Beck, Ward, Mendelson, Mock, \& Erbaugh, 1961) and Geriatric Depression Scale (Yesavage

CONTACT: Mitchell Porter $₫$ mporter1@gardner-webb.edu $\equiv$ The University of Alabama, Carmichael Hall, Box 870231, Tuscaloosa, AL 35487 
et. al., 1982). In this paper, the CES-D (Radloff, 1977) was used. The scale is comprised of 20 items, divided into four factors (depressed, somatic, positive, and interpersonal). The original proposed factor structure for the CES-D is as follows: depressed affect (blues, depressed, lonely, cry, sad, fearful, failure); positive affect (good, hopeful, happy, enjoy); somatic and retarded activity (bothered, appetite, effort, sleep, get going, mind, talk); and interpersonal (unfriendly, dislike). The CES-D was used due to the high internal consistency in noninstitutionalized adults (i.e. is psychometrically robust) as well as its history of being used in a wide range of populations (Cosco, Prina, Stubbs, \& Wu, 2017) making it a good fit for the purposes of this research. The CES-D has historically proven to be one of the most popular forms of assessming depression among researchers (Shafer, 2006).

This four-factor solution has been confirmed in the literature using different sample populations. Husaini, Neff, Harrington, Hughes, and Stone (1980) validated the factor structure in nine rural communities in Tennessee ( $90 \%$ of the sample population was white). Hertzog, Alstine, Usala, Hultsch, and Dixon (1990) confirmed the factor structure in elderly populations (age range 55 to 78) in community-dwelling adults in Canada. Similarly, Lewinsohn, Seeley, Roberts, and Allen (1997) investigated the efficacy of the CES-D as a screener for depression in community-residing older adults (age range $=50-96, N=1,006$ ), and concluded that the internal structure of the four-factor model held.

Gender has also been an area of interest. Knight, Williams, McGee, and Olaman (1997) found that the four-factor model fit the data moderately well in a community sample of 675 women in New Zealand; the majority of the sample was white, with $5 \%$ being either Chinese or Polynesian. Sommel, Given, Kalaian, Shultz, and McCorkle (1993) explored gender bias in the measurement properties in the CES-D. The results indicated that the four-factor structure held, but exhibited signs of gender bias. They created a subset of 15 items that eliminated gender bias and still captured nearly all the information of the 20-item CES-D. Items excluded were failure, talk, unfriendly, crying, and dislike.

Research on the factor structure of the CES-D in minority populations has also been extensive. Roberts (1980) confirmed the four factor structure in a sample containing Anglos $(n=254)$, Blacks $(n=270)$, and Mexican Americans $(n=181)$. Clark, Aneshensel, Freriches, and Morgan (1981) analyzed the effects of gender and age in response to the CES-D items in a sample of 1,000 adults $(61 \%$ White, $20 \%$ Hispanic, $12 \%$ Black, and $7 \%$ other; their results showed that while the interitem correlations were significantly higher for women than in men, the fourfactor solution was confirmed. Williams et. al (2007) examined and confirmed the factor structure in a large cohort of African American women $(N=40,403)$ that were stratified by age ( $<60$ and $\geq 60$ years). Their findings also showed that correlations between factors were weaker in the older group, revealing the while the factor structure was confirmed, it was not invariant.

There have also been challenges to the four-factor model. Miller, Markides, and Black (1997) argue that a two-factor model was a more parsimonious model than the four-factor model for their minority population of elderly Mexican Americans $(N=2,866)$. The factors in their model include Depression Factor (16 items) and Well-being (4 items). Manson, Ackerson, Dick, Baron, and Fleming (1990) discuss the differences in parsimony between a two- and threefactor model in comparison to the four-factor model in a sample of American Indian boarding school students $(N=188$; grades $9-12)$. They concluded that the two- and three- factor models were more desirable in terms of interpretability than the original factor structure. A three-factor solution was also shown to be more parsimonious in a sample of Chinese Americans (Ying, 1988); the factors that were retained were depression, positive affect, and interpersonal. Edman, Danko, Andrade, McArdle, Foster, and Glipa (1999) concluded that a two-factor solution fit reasonably well in a sample of Filipino-American adolescents $(N=243)$; factor 1 combined somatic-retardation, depressed affect, and interpersonal items, and factor 2 consisted of the 
remaining positive items.

The above examples highlight that symptomatology and the concept of depression differs crossculturally, and thus Radloff's original factor structure may not be appropriate for varying subpopulations. The purpose of this paper is to investigate the factor structure of a specific subpopulation (impoverished African-American parents). While research has been done regarding cultural differences in depression, few have investigated impoverished populations; our population sample captures both culture and impoverishment. This is meaningful because items on a scale may not load as expected when the target population has specific traits that distinguish them from the overall population. In other words, these traits may influence the participants understanding and interpretation of the items, and therefore the factor structure may be altered. We investigate how the individual items load to their prescribed factors, and whether there is any disagreement with the results from this study compared to other published works. Based on the literature, the two-, four-, and higher-order factor solutions were the most parsimonious, and therefore we chose to compare these for our research purposes. The research questions for the present paper are:

RQ1: Is the factor structure of the CES-D for impoverished African Americans different from the general population?

RQ2: Which factor structure model best fits the data: two-factor, four-factor, or higher order model?

\section{METHOD}

\subsection{Data and Instrument}

The data come from the Mobile Youth and Poverty Study (MYPS), which consists of datasets related to poverty and adolescent risk in Mobile, AL. The test was administered annually to adolescents in impoverished neighborhoods between the years 1998 and 2011. Over 12,000 youths were enrolled in the MYS, and the age range is 10-18. In addition to the survey data, administrative databases have been accessed in order to provide further information about the participants including school records, court records, and housing records.

The particular set of questions from the MYPS used in the present study is the CES-D. The scale was developed and validated by Radloff (1977), and has gone through slight revisions over the past years. The CES-D scale is a short self-report scale designed to measure depressive symptomatology in the general population. Therefore, the scale should be a useful tool for epidemiologic studies of depression.

\subsection{Participants}

The participants $(N=1,020)$ were African American parents of children who are impoverished and at risk for adolescent behavioral issues. The age range for the sample population was $24-$ 56 years, $\bar{x}=36.2, S D=4.1$.

\subsection{Analyses}

For the statistical analysis, three different models were used. A preliminary exploratory factor analysis (EFA) was used to determine the factor structure for the dataset, and confirmatory factor analyses (CFA) were used to a) confirm the original factor structure of the CES-D that was established in Radloff (1977), b) compare the original four-factor structure to the twofactor structure based on the EFA results, and c) compare the original four-factor structure to a higher order factor model. A random sample of half of the participants $(n 1=510)$ were used in the EFA analysis, and the remaining participants $(n 2=510)$ were used in the CFA analyses. The statistical software package used for the analysis was SAS version 9.4. A parallel analysis was also conducted as an additional measure to check the dimensionality of the CES-D; this was performed in SPSS version 25. 


\subsection{Preliminary Exploratory Factor Analysis}

In order to evaluate the factor structure for this particular population, a two- and four-factor solution was used for the EFA model. Upon inspection of the scree plot, it was determined that a two-factor solution was more efficient; the extraction sums of the squared loadings for the four- factor solution was $56 \%$, while the two-factor solution retained $52.3 \%$. The oblimin rotation method was used for the EFA analysis. The factor solution can be seen in Table 1. All factors loaded above .400 except appetite, showing that items are successfully loading to one of the factors. Lonely double loaded to both factors. Upon inspection of the Cronbach alpha levels, all items were retained in the solution. With a Kaiser-Meyer-Olkin measure of sampling value of .924, we can conclude that factor analysis is appropriate for the data. The determinate of the matrix is .202; therefore, the assumption that there are no linear dependencies in the data is met. Lastly, we did not detect outliers and participants were deleted using pairwise deletion methods.

Parallel Analysis. As an additional measure of dimensionality of the CES-D, a parallel analysis was conducted using the raw data. Based on the comparison of the raw data eigenvalues, mean, and percentile random data eigenvalues, the two-factor solution was the most parsimonious. The raw data eigenvalues were greater than the mean and percentile random data eigenvalues (1.443, 1.265, and 1.187, respectively).

Table 1. Two-factor EFA model

\begin{tabular}{lcc}
\hline Variable & Factor 1 & Factor 2 \\
\hline Dislike & .773 & .119 \\
Mind & .740 & .101 \\
Talk & .678 & .123 \\
Hopeful & .663 & .071 \\
Effort & .660 & .046 \\
Failure & .653 & .054 \\
Happy & .612 & .085 \\
Get going & .598 & .044 \\
Depressed & .566 & .028 \\
Fearful & .557 & .009 \\
Cry & .556 & .001 \\
Unfriendly & .507 & -.036 \\
Bothered & .498 & .042 \\
Sad & .486 & -.006 \\
Good & .477 & .046 \\
Lonely & .331 & .653 \\
Sleep & .229 & .622 \\
Blues & .010 & .502 \\
Enjoy & .005 & .469 \\
Appetite & .145 & -.289 \\
\hline
\end{tabular}

\subsection{Two-factor Confirmatory Factor Analysis}

Based on the two-factor EFA analysis, a CFA model was created. The results of the analysis are illustrated in Table 2. The fit statistics were consistent with those of a moderate-fit model, $\chi 2=1139.32, d f=168, p<.001$, RMSEA $=0.07$, GFI $=0.89$, and CFI $=0.85$. Regarding the individual item loadings, appetite was the only nonsignificant item, with a loading of only .015 . Blues and enjoy yielded relatively weak loadings, with values of .223 and .250, respectively. The remaining items had loadings above .300 , and therefore are loading to the factors that were established in the preliminary EFA analysis. 
Table 2. Two-factor CFA model solution

\begin{tabular}{lcc}
\hline Variable & Factor 1 & Factor 2 \\
\hline Bothered & $.499^{*}$ & \\
Good & $.513^{*}$ & \\
Mind & $.801^{*}$ & \\
Depressed & $.460^{*}$ & \\
Effort & $.684^{*}$ & \\
Hopeful & $.641^{*}$ & \\
Failure & $.668^{*}$ & \\
Fearful & $.633^{*}$ & \\
Happy & $.612^{*}$ & \\
Cry & $.558^{*}$ & \\
Sad & $.489^{*}$ & \\
Dislike & $.835^{*}$ & \\
Get going & $.580^{*}$ & \\
Unfriendly & $.483^{*}$ & \\
Lonely & & $.341^{*}$ \\
Appetite & & .015 \\
Blues & & $.223^{*}$ \\
Talk & & $.538^{*}$ \\
Sleep & & $.496^{*}$ \\
Enjoy & & $.250^{*}$ \\
\hline
\end{tabular}

\subsection{Four-factor Confirmatory Factor Analysis}

Based on the original model by Radloff (1977), a four-factor model was specified. The results are shown in Table 3. The fit statistics were consistent with those of a moderate-fit mode, $\chi 2=$ 1227.77, $d f=164, p<.001$, RMSEA $=0.08, \mathrm{GFI}=0.88$, and CFI $=0.83$. Factor 1 had a weak loading of .094 for blues. Enjoy had a weak factor loading of .093 to factor 2. Appetite had a nonsignificant weak loading of .108 to factor 3 . The remaining items loaded on a factor at or above .300 , so these items on the scale are loading on the factors they were designed to.

Table 3. Four-factor CFA model solution

\begin{tabular}{lcccc}
\hline Variable & Factor 1 & Factor 2 & Factor 3 & Factor 4 \\
\hline Blues & $.094^{*}$ & & & \\
Depressed & $.455^{*}$ & & & \\
Failure & $.645^{*}$ & & & \\
Fearful & $.607^{*}$ & & & \\
Lonely & $.448^{*}$ & & & \\
Cry & $.553^{*}$ & & & \\
Sad & $.471^{*}$ & & & \\
Good & & $.520^{*}$ & & \\
Hopeful & & $.657^{*}$ & & \\
Happy & & $.632^{*}$ & & \\
Enjoy & & $.093^{*}$ & & \\
Bothered & & & $.491^{*}$ & \\
Appetite & & & $.108^{*}$ & \\
Talk & & & $.609^{*}$ & \\
Mind & & & $.787^{*}$ & \\
Sleep & & & $.328^{*}$ & \\
Get going & & & $.579^{*}$ & \\
Effort & & & $.669^{*}$ & \\
Dislike & & & & $.855^{*}$ \\
Unfriendly & & & & $.486^{*}$ \\
\hline
\end{tabular}




\subsection{Higher Order Confirmatory Factor Analysis}

Upon inspection of the covariances among the exogenous variables, it was determined that a higher order model be specified; previous literature regarding the CES-D shows that the four factors developed are assumed to be correlated (Radloff, 1977), adding further justification for a higher order solution. The covariances among the exogenous variables are displayed in Table 4 , and the covariance matrix for the four-factor model is shown in Table 5. The fit statistics were consistent with those of a moderate-fit mode, $\chi 2=1228.86, d f=166, p<.001$, RMSEA $=0.08$, GFI $=0.88$, and $\mathrm{CFI}=0.83$. Appetite and blues had weak loadings on factor $1(.102$ and .066 , respectively). Factor 3 yielded a nonsignificant weak factor loading of .056 for enjoy. The remaining items loaded on a factor at or above .300 , so these items on the scale are loading on the factors they were designed to.

Table 4. Covariances among exogenous variables

\begin{tabular}{lcccc}
\hline & Factor 1 & Factor 2 & Factor 3 & Factor 4 \\
\hline Factor 1 & 1.000 & & & \\
Factor 2 & $.973^{*}$ & 1.000 & & \\
Factor 3 & $1.063^{*}$ & $.993^{*}$ & 1.000 & \\
Factor 4 & $1.002^{*}$ & $.935^{*}$ & $.999^{*}$ & 1.000 \\
\hline
\end{tabular}

* statistically significant

Table 5. Higher order CFA model solution

\begin{tabular}{|c|c|c|c|c|c|}
\hline Variable & Factor 1 & Factor 2 & Factor 3 & Factor 4 & $\begin{array}{r}\text { Genera } \\
\text { Factor }\end{array}$ \\
\hline Blues & $.081 *$ & & & & \\
\hline Depressed & $.568^{*}$ & & & & \\
\hline Failure & $.633^{*}$ & & & & \\
\hline Fearful & $.533^{*}$ & & & & \\
\hline Lonely & $.414^{*}$ & & & & \\
\hline Cry & $.535^{*}$ & & & & \\
\hline Sad & $.463^{*}$ & & & & \\
\hline Good & & $.482 *$ & & & \\
\hline Hopeful & & $.694 *$ & & & \\
\hline Happy & & $.635^{*}$ & & & \\
\hline Enjoy & & $.079 *$ & & & \\
\hline Bothered & & & $.491 *$ & & \\
\hline Appetite & & & $.091 *$ & & \\
\hline Talk & & & $.680 *$ & & \\
\hline Mind & & & $.738 *$ & & \\
\hline Sleep & & & $.310 *$ & & \\
\hline Get going & & & $.591 *$ & & \\
\hline Effort & & & $.678^{*}$ & & \\
\hline Dislike & & & & $.802 *$ & \\
\hline Unfriendly & & & & $.494 *$ & \\
\hline Factor 1 & & & & & $1.027^{*}$ \\
\hline Factor 2 & & & & & $.957^{*}$ \\
\hline Factor 3 & & & & & $1.034 *$ \\
\hline Factor 4 & & & & & $.969^{*}$ \\
\hline
\end{tabular}




\section{DISCUSSION}

In terms of first research question, it appears as the original factor structure of the CES-D is slightly different for this sample population of impoverished African Americans than the general population. The overall model fit indices were adequate, even though there were slight departures from the expected loadings of certain variables. While the original factor structure moderately fit the data, it is worth exploring other factor models that may better fit the current population sample.

In terms of the second research question, deciding on a best fitting model is not as obvious as we would hope. When considering the model fit indices, the two-, four-, and higher- order factor solutions all produce moderately fitting models. However, upon closer inspection of the item loadings, in the four-factor and higher order models, it appears that there are a few items that not contributing to the CES-D the way they were originally designed. Across these models, appetite, blues, and enjoy were either nonsignificant or produced weak loadings to their factors. This not consistent with finding in previous research that looks at the factor structure of the CES-D in minority populations (Roberts, 1980; Williams, 2007). However, in the two-factor solution, appetite was the only item to have a weak loading (.015). Blues and enjoy had adequate loading values (.223 and .250, respectively). We argue that the two-factor model best fits the current data because of the higher overall factor loadings and is the most parsimonious model.

These findings are consistent with previous research that shows a two-factor solution appears to fit the data better with minority populations (e.g. Manson et. al., 1990 and Edman et. al., 1999). It appears as though this population sample of impoverished African-American parents are interpreting the items of the CES-D differently than the population the CES-D was originally developed for and are instead interpreting closely to other minority populations such as American-Indian and Filipino-American. Our recommendation is for researchers to consider using a two-factor solution of the CES-D with African samples from lower socioeconomic backgrounds. However, further research is needed to fully understand the relationship between impoverished African-Americans and other minority groups. Researchers should also continue investigating the effects socioeconomic status has on depression, as well as how the factor structure of the CES-D (and other depression scales, for that matter) are impacted.

When deciding on a best fitting model, the actual loadings need to be considered as well. The loadings as a whole are higher in the two-factor model than the four-factor or higher-order model. The two-factor model produced better loadings, in comparison to the other models, in the following items: bothered, appetite, blues, mind, failure, fearful, sleep, enjoy, cry, and sad. Five of these items are originally on factor 1 (depressed affect), and four originally loaded to factor 3 (somatic and retarded activity) in the four-factor solution established by Radloff (1977). We argue that the two-factor solution is more parsimonious and can better describe the items on the scale related to depression affect and somatic and retarded activity than the four-factor model for this minority population. The factor structure as illustrated in Table 2 is the solution we encourage researhers to considere when evaluating depression via the CES-D in similar samples.

One of most difficult tasks given to a measurement researcher is naming the factors developed using CFA. The relation between the items in factor 1 and factor 2 seems to be feeling versus action, respectively. Items such as bothered, depressed, hopeful, fearful and unfriendly appear to be focused on an individual's feelings or attitude, while appetite, talk, and sleep are more related to individuals' actions. Therefore, we would tentatively name the factors feeling and action.

Regarding the items that failed to adequately load to their respective factors in the four-factor 
and higher-order models, we can offer a few possibilities to why these items are not loading to the factors they were designed to. Perhaps the social context of the impoverished African Americans is affecting their interpretation of the items on the CES-D. Their living environment may not be conducive to experiencing reliable levels of enjoyment. High crime rates, social injustice, and broken families may interfere with their interpretations of blues and enjoy. (Cutrona, et al., 2005). Other studies have found that perceived discrimination and social injustice and poorer mental health could be associated (Brown et. al., 2000). In a longitudinal analysis, Schulz et. al. (2006) found that was a positive relationship between a change in perceived discrimination over time and a change in symptoms of depression, further highlighting the impact that perceived discrimination has on mental health.

Another possible covariate to explore is socioeconomic status (SES) in relation to an individual's depression. Few articles have explored the direct effects of SES on depression, though this is evidence to support the claim that SES is related to depression. Previous research has shown that individuals with higher education can more successfully delay increased levels of depression over time (Miech \& Shanahan, 2000). Additionally, an individual from a high SES may have an interpretation of enjoyment and depression that is vastly different than someone from a low SES (Schnittker, 2008). CFA models such as bifactor models could be used to explore if there is an underlying affect that is related to the factors in the CES-D.

It is worth noting that a possible methodological limitation to our study was the lack of control of age in our population. The range of age in our population was large, and thus it is possible for age to also be an important covariate to explore. However, with a sample mean age of 36 years and $S D$ of 4.2 , we believe that age was not a large enough factor to detrack from our findings. Future studies could investigate age to determine if it is a significant covariate of depression.

\section{ORCID}

\section{Mitchell Porter (iD https://orcid.org/0000-0001-8589-4880 \\ Youn-Jeng Choi (iD https://orcid.org/0000-0001-9803-2681 \\ Sara Tomek (iD https://orcid.org/0000-0003-0705-3087}

\section{REFERENCES}

Beck, A. T., Ward, C. H., Mendelson, M., Mock, J., \& Erbaugh, J. (1961). An inventory for measuring depression. Archives of General Psychiatry, 4(6), 561-571.

Brown, T. N., Williams, D. R., Jackson, J. S., Neighbors, H. W., Torres, M., Sellers, S. L., \& Brown, K. T. (2000). "Being black and feeling blue": The mental health consequences of racial discrimination. Race and Society, 2(2), 117-131.

Campbell, L.L. (2007). CES-D four-factor structure is confirmed, but not invariant, in a large cohort of African American women. Psychiatry Research, 150(2), 173-180.

Cosco, T. D., Prina, M., Stubbs, B., \& Wu, Y. T. (2017). Reliability and validity of the Center for Epidemiologic Studies Depression Scale in a population-based cohort of middle-aged US adults. Journal of Nursing Measurement, 25(3), 476-485.

Clark., V.A., Aneshensel, C.S., Freriches, R.R., \& Morgan., T.M. (1981). Analysis of effects of sex and age in response to items on the CES-D scale. Psychiatry Research, 5(2), 171181.

Cutrona, C. E., Russell, D. W., Brown, P. A., Clark, L. A., Hessling, R. M., \& Gardner, K. A. (2005). Neighborhood context, personality, and stressful life events as predictors of depression among African American women. Journal of Abnormal Psychology, 114(1), 3.

Edman, J. L., Danko, G. P., Andrade, N., McArdle, J. J., Foster, J., \& Glipa, J. (1999). Factor structure of the CES-D (Center for Epidemiologic Studies Depression scale) among 
Filipino-American adolescents. Social Psychiatry and Psychiatric Epidemiology, 34(4), 211-215.

Hamilton, M. (1960). A rating scale for depression. Journal of Neurology, Neurosurgery, and Psychiatry, 23(1), 56.

Hertzog, C., Alstine, J.V., Usala, P.D., Hultsch, D.F., \& Dixon, R. 1990. Measurement Properties of the Center for Epidemiological Studies Depression Scale (CES-D) in Older Populations. Psychological Assessment: A Journal of Consulting and Clinical Psychology, 2(1), 64-72.

Husaini, B.A., Neff, J.A., Harrington, J.B., Hughes, M.D., \& Stone, R.H. (1980). Depression in rural communities: Validating the CES-D scale. Journal of Community Psychology, 8 , 20-27.

Knight, R. G., Williams, S., McGee, R., \& Olaman, S. (1997). Psychometric properties of the Centre for Epidemiologic Studies Depression Scale (CES-D) in a sample of women in middle life. Behaviour research and therapy, 35(4), 373-380.

Lewinsohn, P. M., Seeley, J. R., Roberts, R. E., \& Allen, N. B. (1997). Center for Epidemiologic Studies Depression Scale (CES-D) as a screening instrument for depression among community-residing older adults. Psychology and Aging, 12, 277-287. doi:10.1037/08827974.12.2.277

Manson, S.M., Ackerson, L.M., Dick, R.W., Baron, A.E., and Fleming, C.M. (1990). Depressive symptoms among American Indian adolescents: Psychometric characteristics of the Center for Epidemiologic Studies Depression Scale (CES-D). Psychological Assessment, 2(3), 231-237.

Miech, R. A., \& Shanahan, M. J. (2000). Socioeconomic status and depression over the life course. Journal of health and social behavior, 41(2), 162-176.

Miller, T.Q., Markides, K.S., \& Black, S.A. (1997). The factor structure of the CES-D in two surveys of elderly Mexican Americans. Journal of Gerontology: Social Sciences, 52B(5), S259- S269.

Montgomery, S. A., \& Åsberg, M. A. R. I. E. (1979). A new depression scale designed to be sensitive to change. The British Journal of Psychiatry, 134(4), 382-389.

Radloff, L.S. (1977). The CES-D scale: A self-report depression scale for research in the general population. Applied Psychological Measurement, 1(3), 385-401.

Roberts. R.E. (1980). Reliability of the CES-D scale in different contexts. Psychiatry Research, $2,125-134$.

Santor, D.A. \& Coyne, J.C. (1997). Shortening the CES-D to improve its ability to detect cases of depression. Psychological Assessment, 9(3), 233-243.

Schnittker, J. (2008). Happiness and success: Genes, families, and the psychological effects of socioeconomic position and social support. American Journal of Sociology, 114(S1), S233-S259.

Schulz, A. J., Gravlee, C. C., Williams, D. R., Israel, B. A., Mentz, G., \& Rowe, Z. (2006). Discrimination, symptoms of depression, and self-rated health among African American women in Detroit: results from a longitudinal analysis. American Journal of Public Health, 96(7), 1265-1270.

Shafer, A. B. (2006). Meta-analysis of the factor structures of four depression questionnaires: Beck, CES-D, Hamilton, and Zung. Journal of Clinical Psychology, 62(1), 123-146.

Sommel, M., Given, B.A., Given, C.W., Kalaian, H.A., Schulz, R., \& McCorkle, R. (1993). Gender bias in the measurement properties of the center for epidemiologic studies depression scale (CES-D). Psychiatry Research, 49(3), 239-250

Stroup-Benham, C. A., Lawrence, R. H., \& Trevifio, F. M. (1992). CES-D factor structure among Mexican American and Puerto Rican women from single-and couple-headed households. Hispanic Journal of Behavioral Sciences, 14(3), 310-326. 
Williams, C.D., Taylor, T.R., Makambi, K., Harrell, J., Palmer, J.R., Rosenberg, L., \& AdamsYesavage, J. A., Brink, T. L., Rose, T. L., Lum, O., Huang, V., Adey, M., \& Leirer, V. O. (1982). Development and validation of a geriatric depression screening scale: a preliminary report. Journal of Psychiatric Research, 17(1), 37-49.

Ying, Y. W. (1988). Depressive symptomatology among Chinese-Americans as measured by the CES-D. Journal of Clinical Psychology, 44(5), 739-746. 